\title{
Sözlü çeviride kullanılan teknolojik araçların sınıflandırılması
}

\section{Halil İbrahim BALKUL'}

\section{Şule AKINCI²}

APA: Balkul, H. İ.; Akıncı, Ş. (2019). Sözlü çeviride kullanılan teknolojik araçların sınıflandırılması. RumeliDE Dil ve Edebiyat Araştırmaları Dergisi, (15), 391-446. DOI: 10.2900o/rumelide.580661

\section{$\ddot{\mathbf{O z}}$}

Günümüzde hiç olmadığı kadar artan kültürlerarası etkileşim alanlarında, teknolojik araçlar iletişimsel ihtiyaçlarımızı karşılamak adına oldukça yoğun bir biçimde kullanılmaktadır. Farklı dilleri konuşan insanların iletişim problemlerini çözmek ve çevirmenlerin işlerini kolaylaştırmak adına tasarlanan çeviri teknolojileri üzerine gerçekleştirilen akademik çalışmalar, temel olarak yazılı çeviri teknolojileri alanında yoğunlaşmıştır. Sözlü çeviri teknolojileri araştırma sahasında ise bu bağlamda bir araştırma boşluğu mevcuttur. Halbuki kültürlerarası iletişim engellerini çözmeyi hedefleyen sözlü çeviri alanını, teknolojik gelişmelerden ayrı düşünmek mümkün değildir. Ayrıca, günümüzde sözlü çeviri teknolojileri hızla ilerlemekte ve bir doğal dilden diğer bir doğal dile otomatik sözlü çeviri yapan araçlar bulunmaktadır. Bu çalışmada, sözlü çeviri alanında kullanılan teknolojik araçların kullanım sahası, kullanım amacı ve bu teknolojilerin kullanıcı profilleri incelenmekte ve konuya dair sistematik bir sınıflandırma yapılmaktadır. Bu bağlamda yapılan sınıflandırma, araştırmacıların literatürden elde ettikleri bilgilere ve konuyla ilgili araştırmalarına dayanmaktadır. Araştırma neticesinde, sözlü çeviride kullanılan teknolojik araçlar; sözlü çevirinin farklı türlerinde kullanım durumuna göre, sözlü çevirideki otomasyon derecesine göre, çeviri eyleminde kullanıldıkları sürece göre ve sözlü çeviri eğitiminde kullanılma durumuna göre sınıflandırılmıştır. Sözlü çeviri teknolojilerinin tanıtılmasını ve sınıflandırmasını konu edinen bu çalışmanın, alanda yapılacak ileriki araştırmalara ışık tutması beklenmektedir.

Anahtar kelimeler: Sözlü çeviri, çeviri teknolojileri, sözlü çeviri teknolojileri, sözlü çeviride yenilik.

\section{Classification of technological tools used in interpreting}

\begin{abstract}
In today's ever-increasing intercultural interactions, technological tools are widely used to meet our communication needs. Translation technologies, which were developed to solve communication problems of the people speaking different languages and ease the duties of translators / interpreters, have been heavily discussed in the academic studies about translation rather than interpreting. In this regard, there is a research gap in interpreting technologies research field. Indeed it is impossible to consider interpreting field aiming to break intercultural communication barriers without technological developments. Besides, interpreting technologies are rapidly developing nowadays and we can see the tools that automatically interpret from one natural language to another one. The current paper investigates interpreting technologies' usage areas, usage purposes and user profiles
\end{abstract}

1 Dr. Öğr. Üyesi, Sakarya Üniversitesi, Fen-Edebiyat Fakültesi, Çeviribilim Bölümü (Sakarya, Türkiye), hbalkul@sakarya.edu.tr, ORCID ID: 000o-0002-5775-962X [Makale kayıt tarihi: 06.05.2019-kabul tarihi: 20.06.2019; DOI: $10.29000 /$ rumelide.580661]

2 YL Öğrencisi, Sakarya Üniversitesi, Sosyal Bilimler Enstitüsü, Çeviribilim ABD (Sakarya, Türkiye), sule5494@hotmail.de, ORCID ID: 0000-0002-5140-3542. 
and presents a systematic classification of these technologies. Within this context, the presented classification is mainly based on the insights obtained from the literature and the researchers' reviews. Thus the current research classifies interpreting technologies in four categories, which are: the tools used in different interpreting types, an automation-based classification in interpreting technologies, a process-oriented classification and the tools used in interpreter training. This paper, which aims to introduce and classify interpreting technologies, has the purpose of sheding ligt on the further research in the related literature.

Keywords: Interpreting, translation technologies, interpreting technologies, innovation in interpreting.

\section{Giriş}

Geçmişten günümüze kadar insanoğlunun gündelik yaşamını kolaylaştıran teknik ekipmanlar teknolojik araçlar çatısı altında toplanabilir. Teknolojinin asıl hedefi; insanlara faydalı olması ve onlara gündelik uğraşlarını daha hızlı, zahmetsiz bir şekilde yapmalarını sağlamaktır. Günümüzde gelişen teknolojiyi; sanayi, tarım, eğitim ve iletişim gibi hayatımızın birçok farklı alanında görmekteyiz. Teknolojinin gelişmesi özellikle de bilgisayar, telefon ve internetin insan hayatına girmesiyle her alanda olduğu gibi çeviri alanındada önemli değişiklikleri ve yenilikleri beraberinde getirmiştir. Günümüzde çeviri, geleneklerin dışına çıkmış ve teknolojiye büyük ölçüde ayak uydurmuştur. Profesyonel çeviri dünyasındaki uygulamalara bakıldığında, çeviri projelerinin teknolojik araçlar kullanılarak gerçekleştirildiği görülmektedir (Krş. Zaretskaya, 2015; Christensen \& Schjoldager, 2016; Moorkens \& O’Brien, 2016).

Çeviri alanındaki teknolojik gelişmeler, şüphesiz bulundukları dönemin hâkim teknoloji paradigması altında olmuştur. Günümüzde, yapay zeka uygulamalarının yer aldığı Web 4.o. teknolojisinde ilerlemekte ve çeviri teknolojilerinde gelinen son noktada bu uygulamanın izdüşümlerine rastlamaktayız. Kuşçu (2015) çeviride yapay zekâ uygulamalarını ele aldığı çalışmasında, yapay zekâ uygulamalarının çeviri dünyasına olan etkilerini incelemiş ve bu bağlamda tasarlanan çeviri teknolojilerinin özelliklerini ve çalışma prensiplerini irdelemiştir. Günümüzde yapay zekâ teknolojisiyle tasarlanan makine çevirisi programlarının, eskiye nazaran daha tutarlı çeviri ürünler verdiğini görmekteyiz. O’Hagan (2012:505) ise, teknolojik gelişmelerin çeviri pratiğine iki temel açıdan etkilediğini vurgulamaktadır. Öncelikle, çeviri eylemi esnasında kullanılan teknolojik araçlar geliştirilmiş ve böylelikle çevirmenlerin iş yükü azaltılmıştır. Bilhassa, mikro düzeyde bilgisayar destekli çeviri (BDÇ) araçları sayesinde çevirmenler önceden yapılmış çeviriler vasıtasıyla terimce bulma ya da tutarlı erek metin üretme imkânına sahip olmuşlar, makro düzeyde ise çevirinin gerçekleştirilme ortamı değişmiştir. Günümüzde sanal çeviri platformlarında çeviri işleri yapılabilmekte ve dünyanın farklı yerlerinde bulunan çevirmenler ortak projeler üzerinde farklı çeviri teknolojileri kullanarak çalışabilmektedir.

Teknolojinin çeviri dünyasına etkisini konu edinen akademik araştırmalara bakıldığında, bunların birçoğunun aslında yazılı çeviri teknolojileri kapsamında kaleme alındığı görülmektedir. Alandaki bu çalışmaları, ele aldıkları konular kapsamında tasnif etmek gerekirse şu şekilde bir sınıflandırma yapilabilir:

a) Çeviri teknolojilerinin çeviri dünyasına olan etkisini araştıran çalışmalar (Bkz: O'Hagan ve Ashworth, 2002; Şahin, 2013; Sin-Wai, 2015; Aslan, 2015; Aslan, 2016; Doherty, 2016; Alkan, 2017). 
b) Çeviri teknolojilerinin çeviri eğitimindeki yerini konu edinen çalışmalar (Bkz: Gaspari, 2001; Samson, 2005; Pym, 2006; Austermühl, 2013; Canım-Alkan, 2013;Şan, 2013;Doherty ve Kenny, 2014; Bowker; 2015; Şahin, 2015).

c) Çeviri teknolojilerinin tasarım, uygulama ve değerlendirmesiyle ilgili araştırmalar (Bkz: Hutchins ve Somers, 1992; Bowker ve Barlow, 2004; Garcia, 2009b; Daelemans ve Hoste, 2010; Yavanoğlu ve Sarığlu, 2010; Doherty, 2014; Korkmaz ve Acar, 2017; Ylldırım, 2017).

d) Yerelleştirme alanı ve çeviri teknolojilerinin kullanımını ele alan çalışmalar (Bkz: Esselink, 2000; Odacioğlu, 2017;Schäler, 2010).

Çeviri alanının teknolojiden yararlanması ya da etkisi altında kalması akla sadece yazılı çeviri alanını getirmemelidir. Zira sadece yazılı çeviri değil, sözlü çeviri alanıda teknolojik gelişmelerden etkilenmiştir (Pöchhacker, 2004). Özellikle teknolojik araçların geliştirilmesi ve yaygınlaşması, sözlü çeviri alanında hem çevirinin hızına hem de çevirmen ve müşteriye büyük bir fayda sağlamıştır. Gerek tercümanın sözlü çeviri eylemini gerçekleştirme ortamı (telefonda çeviri ve video konferans çevirisi), gerekse sözlü çeviri eylemi esnasında kullanılan teknolojik araçlar değişmiştir. Sözlü çeviri türlerinden başta simultane/ andaş çeviri olmak üzere ardıl çeviri türünde de teknolojik araç kullanımı artmış ve bu artış sebebiyle çeviri daha hızlı, kaliteli ve sınırları aşan bir hal almıştır.

Sözlü çeviri alanında kullanılan teknolojik araçları konu edinen çalışmalara bakıldığında Pöckhacker (2004), sözlü çeviri alanını tanıttı̆̆ı eserinin bir bölümünde, sözlü çeviri ve teknoloji arasındaki ilişkiyi irdelemektedir. Sözlü çeviride kullanılan teknolojik araçları, öncelikle iletişim teknolojilerinden gelen araçlar bağlamında incelemiş, video-konferans araçlarını ve telefonu bu bağlamda değerlendirmiştir. Sonrasında ise Mehmet Şahin ve Şeyda Eraslan'ın “Sözlü Çeviri Eğitiminde Yeni Yaklaşımlar: Sanal Dünyalar" adlı çalışmalarında ortak projeleri olan TÜBİTAK destekli (Proje No: 114K718) "Sanal Dünyalarda Sözlü Çeviri ve Sözlü Çeviri Eğitimi” başlıklı proje tanıtılmıştır. Proje, üç boyutlu sanal bir ortamda sözlü çeviri ve sözlü çeviri eğitimi için yeni olanaklar ortaya koymayı hedeflemektedir. Projede Türkiye'de sözlü çeviri ve sözlü çeviri eğitimi uygulamalarının genel durumu, eksiklikler ve beklentiler incelenerek, bilimsel açıdan güçlü bir öğrenme ve öğretme ortamının yaratılmasına yönelik çalışmalar yürütülmüştür (Şahin ve Eraslan: 2017).

Balkul (2017) ise çalışmasında, Türkiye'de ve diğer ülkelerde Suriyeli sı̆̆ınmacılara yönelik sunulan yazılı ve sözlü çeviri hizmetlerini karşılaştırarak, sözlü çeviri alanında başvurulan sözlü çeviri uygulamalarına değinmiştir.

Viyana Üniversitesi öğrencisi Ivona Brizar "Speech-to-Speech Translation Apps Ein kritischer Vergleic" adlı yüksek lisans tezinde, üç farklı sözlü çeviri uygulamasını (Jibbigo Translator 2.5.5, VoiceTra4U 3.2 ve SayHi Translate 3.8.2.) sistemsel olarak karşılaştırarak, telefonda sözlü çeviri uygulamaları araştırma sahasını incelemiştir (Brizar, 2014).

Bu çalışmada ise, öncelikle teknolojik gelişmelerin çeviri dünyasında meydana getirdiği değişikliklerin yer aldığı giriş bölümü sunulmakta ve alandaki çalışmalara kısaca değinilmektedir. Daha sonra, sözlü çeviri alanına dair genel bir üst bakışın verildiği birinci bölüm yer almaktadır. Bu bölüm, sözlü çeviri teknolojilerinin daha iyi anlaşılabilmesi açısından çalışma kapsamına alınmıştır. İkinci bölümde ise, sözlü çeviride kullanılan teknolojik araçların kullanım sahası, kullanım amacı ve bu teknolojilerin kullanıcı profilleri incelenmekte ve bu bağlamda bir sınıflandırma modeli sunulmaktadır. Çalışmanın 
sonuç bölümünde ise, çalışmadan elde edilen çıkarımlar sunulmakta ve alanda yapılacak çalışmalar adına tavsiyeler verilmektedir.

\section{Sözlü çeviri alanına genel bakış}

Sözlü çeviri en genel tanımıyla bir dilin, kültürün diğer bir dile, kültüre sözlü olarak aktarılmasıdır. Doğan (2009: VII) ise, oldukça detaylı ve kapsamlı bir şekilde sözlü çeviriyi şu şekilde tanımlamaktadır: "Seri düşünebilen, aynı anda birkaç işe odaklanabilen, üst düzey zihinsel becerilere sahip, dinamik, yaşama merak duyan, öğrenmeyi, değişimi, hareketi seven, riske atılmaktan korkmayan, zor koşullardan ve yoğun stresten yılmayan ve bunlarla başa çıkabilme gücünü içinde hisseden, iletişimde farklı diller ve kültürlerarasında aracı olmanın coşkusunu özleyen insan tipinin, tadına doyamadan yaşayacağı, ona bilginin tam ortasında ve dünyanın önünde olma firsatını sağlayacak dolu dolu bir serüven”.

Yukarıdaki tanımından anlaşılacă̆ı üzere sözlü çeviri eylemi; gerçekleştirilmesi zahmetli, riskli, hataların en az hatta yok saylacak nitekte olması gerektiği, deneyim, bilgi ve beceri gerektiren bir eylemdir. Yazll çeviride olduğu gibi sözlü çeviri de kültürlerarasında önemli bir köprü görevi görmektedir. İnsanlık tarihinin var olduğu günden bu yana sözlü çeviri eyleminin gerçekleştiğini söyleyebiliriz. Günümüzde ise uluslararası ilişkiler hiç olmadığı kadar artmış ve buna paralel olarak uluslararası ticarette ciddi manada ivme kazanmıştır. Bu gelişmelerin izdüşümünde ise, kültürlerarası iletişim uzmanı (Maanteeri, 1984) olarak kabul edilen tercümanlara olan ihtiyaç oldukça fazla artmıştır. Diriker (2009)'in vurguladığı üzere, sözlü çeviri araştırmalarında öncelerde sadece sözlü çeviri eylemi esnasında tercümanın tecrübe ettiği bilişsel süreçler inceleniyorken, günümüzde sözlü çevirinin kültürel ve toplumsal boyutları mercek altına alınmış ve bu çalışmalar alanın gelişmesine zemin hazırlamıştır.

Gile (1995: 162), sözlü çeviri alanındaki bilimsel gelişim süreçlerini şu şekilde sıralamaktadır:

- İlk süreç, bilim öncesi dönem (préscientifique période) olarak karşımıza çıkmaktadır.

- Psikoloji dalının sözlü çeviriye hâkim olduğu süreç, deneysel psikoloji dönemi (la période de psychologie experimentale) olarak kabul edilir.

- Uzmanlar döneminde (la période des experts) konferans çevirmenleri, uygulamayla elde ettikleri bilgilerle alanlarının incelemelerini kendileri yapmaya başlar.

- Uzmanlar dönemi, yerini yenileşme dönemine (la période du renouvellement) bırakır.

Farklı konferanslarda disiplinlerarasılık oldukça yoğun olarak öne çıkar. Gile, 1990 lı yılların başında sözlü çeviri alanında disiplinlerarası bir açılımın olması gerektiğini savunur ve daha bilimsel, sistematik ve uygulamanın önemini vurgulayan bir yaklaşım talebinde bulunur.

Çeviri eyleminin daha iyi, hızlı ve sınırları aşan bir duruma gelmesi için ise teknolojik araçlara ihtiyaç duyulur. Zira teknolojik araçlar, yazılı çeviri eylemini gerçekleştiren çevirmenlerin yanı sıra sözlü çeviri yapan çevirmenlerede fayda sağlamaktadır. Günümüze kadar ilerleyerek gelen teknoloji ve bu ilerlemeyle sözlü çeviri alanına giren teknolojik araçlar, çevirmenlerin işini kolaylaştırmakla beraber sözlü çeviriyi geleneklerin dışına çıkarmıştır. Bu araçlar sayesinde hem çevirmenler hem de çeviri hizmeti alan kişiler, zaman ve mekan olgularını geride bırakmışlardır. Sözlü çeviriyi temel olarak dört üst alana ayırmak mümkündür. Bu dört üst alan sırasıyla: andaş/simultane çeviri, ardıl çeviri, toplum 
çevirmenliği ve konferans çevirmenliğidir. Fakat bu türlerde kendi içerisinde alt alanlara ayrllabilmektedir.

Andaş çeviri: Konuşmacı konuşurken onunla aynı anda çeviri işleminin gerçekleştirildiği çeviri türüdür. Ülkemiz çeviri ortamında daha çok 'simultane çeviri' ya da 'eşzamanlı çeviri' şeklinde anılmaktadır (Doğan, 2009). Andaş çeviri türleri şunlardır: kabiniçi andaş çeviri, kabindışı andaş çeviri, fısıldayarak çeviri, televizyondan andaş çeviri ve video-konferans çevirisi.

Ardıl çeviri: Bu tür çeviri, konuşmacının yaptığı konuşmayı dinleyen çevirmenin, gerektiği yerde not alması, konuşma bitiminde de belleğinde tuttukları ile aldığı notları birleştirerek dinleyicilere diğer dilden aktarması ile gerçekleştirilir. (Doğan, 2002a) Ardıl çeviri türleri şunlardır: İrtibat çevirisi, ikili görüşme çevirisi, refakat çevirisi, telefonla sözlü çeviri, konferans çevirisi, spor çevirmenliği ve medya çevirmenliği.

Toplum Çevirmenliği: Andaş, ardıl veya fısıldayarak yapılmak üzere toplumsal olan her olay ve ortamda karşımıza çıkmaktadır. Yani Edwards (1995) 'de belirttiği üzere: "Devletin resmi kurumlarıyla bireyler arasındaki iletişimde çeviriye gereksinim duyulan okullar, hastaneler, devlet daireleri, gümrük ve pasaport kontrol noktaları ya da emniyet merkezleri gibi ortamlarda yapıldığı yerler" de toplum çevirmenliğine rastlamak mümkündür. Bu çeviri türünde kullanılan teknolojik araçlar yapılan çeviriye göre değişim gösterir.

Konferans Çevirmenliği: Konferans çevirmenliğinde başta andaş sonrasında ise ardıl çeviri yaygın olarak kullanılan çeviri türleridir. Konferans çevirmenliği tercümanlık mesleği içerisinde özellikle üzerinde durulan bir meslek türüdür. AAIC ( Uluslararası Konferans Tercümanları Derneği) ve Türkiye Konferans Tercümanları Derneği, konferans tercümanı olarak çalışanları bir araya getirerek, çalışma koşulları ve meslek kurallarıyla ilgili uluslararası standartlara uygun ilkeleri oluşturup yerleştirerek, bu meslek türüne değer katmışlardır.

\section{Sözlü çeviride kullanılan teknolojik araçların sınıflandırılması}

Araştırmanın bu bölümü, sözlü çeviride kullanılan teknolojik araçların araştırmacıların literatür okumalarından esinlenerek oluşturdukları sınıflandırmasını içermektedir. Bu bağlamda sözlü çeviride kullanılan teknolojik araçlar; farklı sözlü çeviri türlerinde kullanım alanlarına göre, sözlü çevirinin hangi sürecinde kullanıldıklarına göre, sözlü çeviride kullanım otomasyon derecesine göre ve sözlü çeviri eğitiminde kullanım alanına göre dört kategoride incelenmektedir.

\subsection{Farklı çeviri türlerinde kullanılan sözlü çeviri teknolojileri}

\subsubsection{Kabiniçi andaş çeviri}

Bu çeviri en az 1 en fazla 3 tercümanın donanımı ve tasarımı özel yapılmış kulaklıklı, mikrofonlu ve ekipmanlı bir kabin içerisinde yaptığı andaş çeviri türüdür. Tercümanlar kendi aralarında 20-30 dakikada bir değişiklik yaparlar. Bu tür çeviri, konuşmacıların fazla olduğu ya da birden fazla dilden çeviri gerektiği toplantılarda tercih edilir. Kabiniçi andaş çeviri türünde oldukça fazla teknolojik araçlardan yararlanılır. Öyle ki bu kullanılan teknolojik araçların belirli standartları mevcuttur. Bu standartlar AICC (Uluslararası Konferans Tercümanları Derneği) tarafından belirlenniştir. Kabiniçi andaş çeviride bir de kabinlerin sabit veya taşınabilir olma durumları vardır. Bu durumlarda kullanılan ekipman değiş̧mez fakat AIIC'nin belirlemiş olduğu standartlar değişim gösterir. Elektronik teknik 
cihazlarda ise herhangi bir değişiklik olmaz. İki tür kabinde de CEI 60914 standartlarına uyulması şarttır.

ISO 2603 eş zamanlı (simültane) tercüme için sabit kabinler standardı, Türk standardı haline getirilmiştir (Türkiye Konferans Tercümanları Derneği). Bu kabinler içerisinde bulunan teknolojik araçlar şu şekildedir: kontrol paneli, kulaklık, mikrofon, görüntü ekranı, aydınlatma sistemi, havalandırma sistemi.

ISO 4043 eş zamanlı (simültane) tercüme için taşınabilir kabinler standardı, Türk standardı haline getirilmiştir. Taşınabilir kabinler: portatif, parçalara ayrılan ve konferans salonuna kurulan kabinlerdir. Taşınabilir kabinler dört kurala uygun şekilde tasarlanmalıdır: (Türkiye Konferans Tercümanları Derneği).

- Eş zamanlı olarak konuşulan farklı diller arasında akustik ayrımın sağlanması

- Konferans tercümanlarıyla toplantı katılımcıları arasında iyi bir görsel temas ve iki yönlü ses iletişimi sağlanması

- Ofisleri eş zamanlı tercüme kabinleri olan konferans tercümanlarının gün boyunca dikkatlerini yoğunlaştırabilmelerine yardımcı olacak yeterli çalışma koşullarının sağlanması

- Kabinin kolay taşınabilmesi, kurulabilmesi, hafif ve sağlam olması

Taşınabilir kabinlerde de sabit kabinlerde bulunan teknolojik araçlar kullanılır. Taşınabilir kabinler ise tercüme şirketleri tarafından dünyanın birçok yerinde ve de ülkemizde kiralanmaktadır. Bu kiralama sözlü tercüman ve simultane çeviri ekipmanı şeklinde olur.

\section{Örnek: Nova Konferans Çevirmenliği Hizmetleri}

- Bosch DCN dijital konferans ağ sistemleri:

- Simultane çeviri kontrol ünitesi

— Simultane çeviri yazılım modülü

- Digital infrared vericiler

- Bosch marka digital alıcılar (infrared)

- Bosch DCN delege mikrofonları

- Sennheiser ve JBL ses sistemleri:

- 600-90oW speaker sistemler

- Sesmixerleri

- Yaka ve gezici mikrofonlar

- Çevirmenkabinleri:

- Ses yalıtımlı ve havalandırmalı

- Ergonomik dizayn

\subsubsection{Televizyondan andaş çeviri}

$\mathrm{Bu}$, televizyon ekranından farklı dilde yapılan bir konuşmayı, dünyanın değişik yerlerindeki televizyon izleyicilerine kendi dillerinde anında ulaştırabilmek amacıyla gerçekleştirilen bir andaş çeviri türüdür. $\mathrm{Bu}$ tür çeviride çevirmen, televizyon stüdyosunda kendine ayrılan yere oturur, kulaklık ve mikrofon kullanır ama görüntü televizyondan gelmektedir (Doğan, 2009). Kullanılan teknolojik araçlar şu şekildedir: kulaklık, mikrofon, televizyon. 


\subsubsection{Video-konferans çevirisi}

Bu çeviri türü, günümüz teknolojisindeki son değişiklikler ile birbirinden uzak yerlerde olup, çeşitli nedenlerle bir araya gelemeyen insanlar arasında iletişimi ve konferansı mümkün kılmasıyla gündeme gelmiştir (Doğan, 2009). Teknolojik araç olarak konferansın yapılacağı cihaz yeterli olacaktır. Telefon, dizüstü bilgisayar ve tablet bu noktada örnek olarak gösterilebilir.

\subsubsection{Fısıldayarak çeviri/ fısıltı çevirisi}

$\mathrm{Bu}$ çeviri türü andaş çevirinin alt alanına girer. Andaş çeviride olduğu gibi konuşmacının söyledikleri aynı anda çevirilir. Çevirmenler az sayıda dinleyicinin arkasında ya da arasında oturarak çeviriyi fısıltıyla, diğer katılımcıları rahatsız etmeyecek şekilde andaş çeviri kullanarak yaparlar. Fısıltı çevirisinde, diğer çevirilerde olduğu gibi çevirmenin konuşmacıyı dikkatli dinlemesi gerekir. Fakat çeviri yapılan ortam, teknik ekipmanlardan kaynaklanan bir sorun neticesinde çevirmenin konuşmacıyı net olarak duyma problemi ortaya çıabilir. Bu yüzden fisıltı çevirisini gerçekleştirecek çevirmene Infoport cihazını kullanması tavsiye edilebilir. Infoport cihazı, taşınabilir bir çeviri ekipmanıdır. Fabrika ziyaretlerinde ve saha gezilerinde yapılacak eşlik çevirilerinde özellikle de fisıltı çevirisi sırasında kullanmak çok akıllıcadır çünkü fısıltı yapan çevirmen sürekli eğilerek bir kişinin kulağına simultane çeviri yapmaya çalışır. Oysa infoport kullanılırsa hem eğilmek gerekmez hem de çevirmen biraz daha geride duracağı için çevredekiler fisıltıdan rahatsız olmazlar.

\subsubsection{Ardıl çeviri}

Ardıl çeviride kullanılan teknolojik araçlar andaş çeviriye oranla daha kısıtlıdır. Fakat teknolojinin günümüzde katettiği gelişmeler sayesinde ardıl çeviri içinde teknolojik uygulamalar ve araçlar geliştirilmiştir. Ardıl çevirinin başarılı bir şekilde gerçekleştirilmesi, ilk olarak çevirmenin hafızasının kuvvetli oluşu sonrasında ise çevirmenin hızlı ve etkili not almasına bağlıdır. Çevirmenin daha kolay not alması adına ise telefon veya tablette kullanılan not alma programları geliştirilmiştir. Bu programlara örnek olarak skecht, notebook ve bamnoo paper verilebilir. Ardıl çeviri sürecinde önemli olan bir diğer konu ise yanlış çevrilen bir kelimenin dahi konuşmanın yanlış anlaşılmasına ve amacından sapmasına sebep olabilmesidir. Bu sebeple çevirmenlerin konuşmacının sözlerini çok dikkatli dinlemeleri ve dikkatli bir şekilde aktarmaları gerekmektedir. Aktarma sırasında ise çevirmen sesinin daha net duyulması adına mikrofon tercihini iyi kullanmalıdır. Bunların yanı sıra teknolojik olmayan fakat ardıl çeviride çevirmen tarafından genellikle kullanılan araçlar not defteri, kağıt ve kalemdir.

\subsubsection{Telefonla sözlü çeviri}

Telefonla sözlü çeviri, ABD’de 1989'dan beri telefon şirketi tarafından kendine özel bir sistemle ve bünyesindeki çevirmenlerle 140 dilde 24 saat sağlanan bir hizmettir. Özellikle iş dünyasında ve acil sağlık durumlarında başvurulmaktadır (Doğan, 2009). Fakat bu durumların yanı sıra günümüzde büyük bir konu olan mültecilerinde bu uygulamaya başvurduklarını görmekteyiz. Özellikle de göçmenlere ve mültecilere yönelik birçok telefondan sözlü çeviri uygulaması geliştirilmiştir. Bu uygulamalara örnek olarak: Translator-Pool, ETCall, RefuChat, Bridge, Tarjimly uygulamaları verilebilir. 


\subsection{Sözlü çeviride otomasyon derecesine göre teknolojik araçlar}

\subsubsection{Bilgisayar destekli sözlü çeviri}

Dünyanın her yerinde her çevirmen, çevirmen adayı, çeviri hizmeti veren kişiler tarafından kullanılan bilgisayar destekli çeviri programları, yazılı çeviri alanında olduğu gibi sözlü çeviri alanında da oldukça yaygın bir şekilde kullanılmaktadır. Bu programlar, yalnızca yazılı ve sözlü çeviri alanlarına özel tasarlanmış ya da iki alanın ortak kullanabileceği programlar olarak tasarlanıp hayata geçirilmiştir. Sözlü çeviri alanında oluşturulan bilgisayar destekli programlar genellikle çeviri bellekleri şeklindedir. Her iki çeviri türü için kullanılan çeviri belleklerine örnek olarak Across, MemoQ ve SDL Trados verilebilir. Bu çeviri bellekleri, özellikle konferans öncesi hazırlık aşamasında terim listesi oluşturmak için oldukça elverişlidir.

Interplex çeviri bellek programı da ortak alan için kullanıma açıktır. Interplex hem tercümanlar hem de çevirmenler için tasarlanmış bir sözlük yönetimi programıdır. Interplex, izole edilmiş bir kelime listesi tutmak yerine, belirli bir konuya veya alana ilişkin tüm terimleri anında aranabilecek bir sözlükte gruplandırmaya izin verir. Profesyonel, serbest tercümanlar ya da tercüman adayları tarafından kullanılan bu sistem telefona, tablete ya da bilgisayara indirilip, bir ücret karşılığında kullanıma açıktır.

InterpretBank 5 ise sözlü çeviri alanına hitap eden çeviri belleği örneklerinden bir tanesidir. Özellikle profesyonel tercümanlar için tasarlanmış bu çeviri belleği programı, windows ve macOS için bir masaüstü aracıdır. İki farklı sürümüyle hem serbest tercümanlara hem de kurumlara hizmet sağlamaktadır. InterpretBank 5, özel sözlükler oluşturmak, yönetmek ve bunlara erişmek için serbest tercümanlara ve kurumlara hazır bir çözüm sunmakta ve çeviri hizmetini veren tercümanın işini kolaylaştırmaktadır.

Intragloss ise bir diğer sözlü çeviri bellek sistemlerinden bir tanesidir. Intragloss, tercümanın hazırlık belgesinden veya web sitesinden sözlükler oluşturur. Belgeden sorun teşkil eden terimlerin listesini hızlı bir şekilde not alır ve kolayca tam teşekküllü çok dilli sözlükler oluşturur. Bu sözlüklere alan sözlükleride dahil olur. Bu sistemde InterpretBank 5 'in olduğu gibi serbest tercümanlar, profesyonel tercümanlar ve kurumlar tarafindan başvurulan bir sistemdir.

\subsubsection{Otomatik sözlü çeviri programları}

$\mathrm{Bu}$ programları iki farklı başlık altında değerlendirmek doğru olacaktır. Zira bu programların bazılarından bilgisayar, tablet ya da telefon aracılığıyla hizmet almak ve vermek mümkünken, bazılarına mobil uygulaması olarak sadece telefondan ulaşılır.

Birçok farklı teknolojik araç vasıtasıyla ulaşılabilir otomatik sözlü çeviri programı olarak akla ilk gelenlerden biri Google Translate’tir. Google tarafından yayınlanan Google Translate ya da Türkçe adıyla Google Çeviri uygulaması, Android ve iOS mobil cihazlarınıza ücretsiz olarak indirilebilen, bir yabancı dil sözlüğü ve sesli çeviri aracı olarak kullanılır. Herkese açık olan bu program, her çeviri hizmeti almak ya da vermek isteyen kişi ya da kurum tarafından kullanılabilir niteliktedir. Fakat çevirilerin hata payının olması nedeniyle özellikle profesyonel çevirmenler tarafından başvurulan bir program değildir. Program, 100’ü aşkın dilde yazılı çeviri 50’den fazla sözlü çeviri hizmeti vermektedir.

Microsoft Translator isimli çeviri uygulaması bilgisayarda olduğu gibi iOS ve Android'lerde de kullanıma açlktır. Apple Watch ve Android Wear ile uyumlu olan Microsoft Translator sayesinde, 50 farklı dil 
arasında anında çeviri yapılabilmektedir. Konuşulanı algılama ve sesli çeviri yapma özelliği bulunan Microsoft Translator, kullanıcılarına yabancı gelen bir dili konuşan kişilerle anında kolayca iletişim kurmayı sağlamaktadır. Fakat birçok programda olduğu gibi bu hizmeti almak içinde internet bağlantısına gerek duyulmaktadır. Ayrıca Google Translate'de olduğu gibi bu programda da oluşabilecek çeviri hatalarından dolayı profesyonel tercümanlar tarafından tercih edilen bir program değildir. $\mathrm{Bu}$ program daha çok hızlı bir tercüme hizmetine ve farklı bir dilde iletişim kurma ihtiyacı olan kullanıcılar tarafından kullanılır. 50 farklı dilde tercüme yapması programın tercih edilmesindeki en büyük etkendir.

Bir dil çeviri uygulaması olan iTranslate, İngilizce Türkçe çevirinin yanı sıra 50 dilde çeviri yapmaktadır. Ses tanıma ve sesli çeviri özelliğine sahip iTranslate uygulaması, hafif ve hızlı olmasının yanı sıra, Android 2.3.3 ve üzeri bulunan cihazlara ücretsiz olarak yüklenebilmektedir. Her çeviri hizmeti almak ya da vermek isteyen kişiler tarafından kullanılabilir niteliktedir.

Bir diğer örnek uygulama ise Translate.com tarafından geliştirilen ve Google Translate' in en güçlü rakibi olan Translate, başarılı arayüzü ve kullanım kolaylığı ile dikkat çekmektedir. İnsan çevirisi özelliği ile en doğru çevirileri yapabilen uygulamanın en iyi çeviri uygulaması olduğu söylenebilir. İngilizce Türkçe çevirinin yanı sıra 90'a yakın dilde çeviri yapabilme özelliğine sahip Translate, Android 2.2 ve üzeri bulunan cihazlara ücretsiz olarak yüklenebilmektedir.

Yandex'in Google Translate rakibi olarak geliştirdiği Yandex Translate, henüz Google Translate kadar fazla dil desteği sunmuyor olsa da İngilizce Türkçe çeviri dahil 40 dilde çeviri yapabilmektedir. Ayrıca pek çok özelliği otomatik olarak gerçekleştiren Yandex Translate, hızlı çalışmanın yanı sıra, Android 2.3 ve üzeri bulunan cihazlara ücretsiz olarak indirilebilmektedir.

Otomatik sözlü çeviri yapan mobil uygulamalar ise hem iOS hem de androidlerde mevcuttur. Apolan Apps Türkçe adıyla Konuş \& Çevir, dünyanın herhangi bir köşesinde etkin bir biçimde iletişim kurmaya olanak sağlayan bir ses ve metin tercümanıdır. İçerisinde, Apple ses tanıma teknolojisi desteği, metin çevirileri için 117 dil, ses çevirileri için 54 dil, metinden metine modu için dil algılama, iCloud birleştirmesi ve ses ayarları hizmetleri vardır. 34 dilde andaş çeviri hizmeti de veren bu uygulama ücretsiz bir sürüme sahiptir. Fakat sürekli ve kaliteli bir hizmet için abonelik ve alınmak istenen hizmete göre bir ücret ödenmelidir. Apolan Apps daha çok sürekli yurt dışına çıkan, yabancılarla sürekli iletişim halinde olan ya da iletişime geçmek isteyen kişiler, tercümanlık öğrencileri, farklı bir ülkede yaşayan kişiler tarafından kullanılabilir bir programdır.

Otomatik sözlü çeviri mobil uygulamaları birçok farklı kişi tarafından kullanılmakta, birçok farklı ihtiyaçtan dolayı bu uygulamalara başvurulmaktadır ya da farklı ihtiyaçlar doğrultusunda bu uygulamalar tasarlanmaktadır. Söz konusu sözlü çeviri mobil uygulamalarına mülteciler, serbest tercümanlar, profesyonel tercümanlar, gönüllü tercümanlar, tercümanlık öğrencileri ya da mültecilerle iletişime geçmek isteyen başka kişiler başvurabilir.

Günümüzün önemli bir konusu olan mülteciler için ise dünyanın birçok yerinde kullanabilecekleri mobil uygulamalar tasarlanmış ve hayata geçirilmiştir. Bu bağlamda Balkul (2018), Suriyeli mülteci krizi için tasarlanan çeviri uygulamalarını incelemiştir. Bu mobil uygulamaların bazıları ise bir dilden diğer bir dile otomatik sözlü çeviri gerçekleştirmektedir. Turkcell tarafından tasarlanan Merhaba Umut uygulaması ve Young Guru Academy tarafından geliştirilen We Talk uygulaması bu bağlamda örnek gösterilebilir. Bu uygulamalar, sığınmacı ve mülteciler için tasarlandığından dolayı ücretsizdir ve 
bilhassa Türkçe'nin çalışma dili olarak kullanılıyor olması önemlidir (Arapça-Türkçe; Türkçe-Arapça). Araştırmacı tarafından incelenen diğer çeviri teknolojileri arasında, yazarın "aracı çeviri teknolojileri" olarak ifade ettiği çeviri araçlarıda bulunmaktadır. Bu araçlar, insani yardım projelerinde ve mülteci krizi gibi kriz ortamlarında, gerek yazılı gerekse sözlü çeviri ihtiyacı duyan bireylerle (örn. sığınmacılar, yardım gönüllüleri ya da resmi görevliler) gönüllü çevirmen ve tercümanları buluşturmaktadır. Yazılı ya da sözlü çeviriye ihtiyaç duyan birey, aracı çeviri teknolojileri (örn. Tarjimly ve Bridge) vasıtasıyla internet üzerinden istek göndermekte ve sistemde kayıtll olan ve o an için müsait olan gönüllü çevirmen / tercüman tarafından yazılı ya da sözlü çeviri isteği yanıtlanmaktadır. Gerekli olduğu ve resmi prosedürlerin el verdiği ortamlarda bu gönüllü çevirmenler / tercümanlar çeviri isteğinde bulunan kişiler için sözlü çeviri eylemi gerçekleştirmek için ilgili makamda buluşmaktadırlar. Elbette güvenlik önlemleri gereği, bu prosedür bahsedilen aracı çeviri teknolojileri ve resmi makamlar tarafından kayıt altına alınmaktadır.

\subsection{Süreç odaklı sözlü çeviri teknolojileri}

Sözlü çeviride kullanılan teknolojik araçların sınıflandırması yapılırken, bu araçların sözlü çevirinin hangi safhasında kullanıldığının saptanması oldukça büyük bir önem taşımaktadır. Buna göre, çalışmamızın bu bölümünde sözlü çeviride kullanılan araçları; süreç öncesi (hazırlık aşaması) kullanılan araçlar, süreç esnasında (sözlü çeviri eylemi) kullanılan araçlar ve süreç sonrası (değerlendirme) kullanılan araçlar olarak üç gruba ayırmaktayız.

\subsubsection{Süreç öncesi kullanılan araçlar}

$\mathrm{Bu}$ aşama, bilhassa sözlü çeviri sürecinin başarıyla tamamlanması için oldukça büyük bir öneme sahiptir. Tercümanın sözlü çeviri eylemi öncesinde kendisine sağlanan konuşma metnini incelemesi ve gerek oradaki teknik terimlere ya da uzmanlık alan konularına bakmasına olanak veren araçlar bu bağlamda değerlendirilebilir. LookUp, ConvertUnits, Interplex UE ve InterpretBank bu bağlamda örnek verilebilecek araçlardır. Şüphesiz, bu araçların kullanılma durumu sözlü çeviri türüne göre değişkenlik arz etmektedir. Örneğin, konferans çevirisi ve mahkeme çevirisi gibi sözlü çeviri türlerinde bu tür araçlar çok rahatlıkla kullanılabilirken; diyalog çevirisi, telefonda çeviri ve refakat çevirisi gibi öncesinden bağlam hakkında çok fazla bilginin verilmediği sözlü çeviri türlerinde kullanılması zor olmaktadır. Ayrıca bu sınıflandırmada ele alınan araçlar, yazılı çeviride de rahatlıkla kullanılmaktadır. Bu yönüyle, bu araçlar yazılı ve sözlü çeviride ortaktır. Fakat, bu tür araçlar yazılı çeviride gerek süreç öncesi gerekse süreç esnasında kullanılabilirken; sözlü çeviride ise eylemin doğası gereği sadece süreç öncesinde kullanılabilmektedir.

\subsubsection{Süreç esnasında kullanılan araçlar}

$\mathrm{Bu}$ aşamada kullanılan araçlar, özellikle farklı sözlü çeviri türlerine göre değişiklik göstermektedir. Örneğin, ardıl çeviride not alma aracı olarak kullanılan dijital kalem uygulaması, andaş çeviri esnasında tercih edilmemektedir. Ardıl çeviride yine farklı not alma uygulamaları ve araçları mevcuttur. Bunlara örnek olarak; Evernote, Sky Wifi Smartpen, Echo Smartpen ve PenSupremacy gösterilebilir (Costa, Corpas-Pastor ve Duran-Munes, 2014). Farklı çeviri türlerinde süreç esnasında kullanılan araçlara örnek vermek gerekirse; rekafat çevirisinde kulaklık, telefonda çeviride telefon, video konferans çevirisinde internet ve bilgisayar dile getirilebilir. Ayrıca, toplum çevirmenlğinde kullanılan aracı çeviri teknolojileri bu bağlamda, tercümanların süreç esnasında tercih ettikleri araçlardandır. 


\subsubsection{Süreç sonrasında kullanılan araçlar}

Sözlü çeviri türlerinin kendilerine has özellikleri ve iç dinamikleri olduğu göz önünde bulundurulduğunda, her sözlü çeviri türünde süreç sonrası teknolojik araçların kullanımından bahsetmemiz mümkün olmayacaktır. Fakat bilhassa konferans çevirmenliği, mahkeme çevirmenliği ve toplum çevirmenliğinin bazı alt türlerinde çeviri eyleminin doğası gereği resmi ortamlarda geçtiği varsayılacak olursa, bazı teknolojik ekipmanların çeviri sürecinin nasıl geçtiğini kayıt altına almak ve arşivlemek için kullanıldığını söyleyebiliriz. Bu bağlamda kullanılan araçlar ise ses ve görüntü kayıt cihazları olacaktır. Örneğin sığınma başvurusunda bulunan bir mülteci ile yapılan görüşme esnasındaki çeviri eyleminin kayıt altına alınması hem tercümanın hem de mültecinin ve görüşmeyi yapan memurun faydasına olacaktır. Çünkü ileride karşılaşlabilecek yasal itiraz ve belgelendirme süreçleri böylelikle daha şeffaf ele alınabilecektir. Bunun yanında, tercümanlara kendi performanslarını değerlendirme olanağı da sağlanmış olacaktır. Her ne kadar çeviri eleştirisi denildiğinde, yazılı çeviri eleştirisi anlaşılsa da sözlü çeviri eleştirisi de bu bağlamda gerçekleştirilebilir. Bu durum yukarıda bahsedildiği gibi tercümanların özdeğerlendirmesi düzeyinde olabileceği gibi, aynı zamanda dış otoritereler tarafından tercümanın performansını değerlendirmede de kullanılabilir.

Süreç sonrasında ayrıca sözlü ve görsel materyallerde geçen konuşmaların yazıya dökülmesini sağlayan teknolojik araçlar da kullanılabilir. Bu bağlamda "Google Dökümanlar" ve "Voicedocs" gibi bilindik araçlar işe yarayacaktır. Böylelikle sözlü çeviri süreci sadece belirli ortamda gerçekleşip bir daha anılmayan bir eylem olmaktan çıkacak ve alandaki değişik araştırmalara kapı aralayacaktır.

\subsection{Sözlü çeviri eğitiminde kullanılan teknolojik araçlar}

Teknolojinin gelişmesiyle iletişimin önemi giderek artmıştır. Çeviri ise, iletişimin önemli bir unsuru olarak teknolojiden etkilenmiştir. Çeviri eğitiminde ise hem yazılı hem de sözlü çeviri eğitimi teknolojiden faydalanmaktadır. Özellikle de sözlü çeviri eğitiminde teknoloji kullanımı fazlasıyla yoğundur. 1990’lı yılların sonuna kadar çoğu çevirmen okulunda kullanılan en ileri teknoloji ses kasetleri ve tepegözler iken bugün daha farklı teknolojiler yaygın olarak kullanılmaktadır (Şahin, 2013).

Ülkemizde ve dünyanın birçok yerinde sözlü çeviri eğitimi veren üniversitelere bakıldığında, bugünkü kullanılan farklı teknolojik araçlara rastlamak mümkündür. Özellikle de bölümlerdeki andaş çeviri laboratuvarlarında bu araçlar yoğun bir şekilde kullanılmaktadır. Bu laboratuvarlar öğrencileri gerçeğe yakın ortamda sözlü çeviriye hazırlamak amacıyla kurulmuştur. Bilgisayar sistemiyle donatılmış, internet bağlantısına sahip ve uydu televizyon yayınlarından yararlanmaya uygun bir düzeneneğe sahip laboratuvarlarda öğrenciler andaş çeviri alıştırmalarını kaydederek kendilerini geliştirmek amacıyla başarılarını daha sonra değerlendirme olanağına sahiptir. Bu laboratuvarlar andaş çeviri eğitiminin yanı sıra ardıl ve yazılı metinden sözlü çeviri eğitimi için de kullanılır. Burada bulunan kabinler aracılığıyla öğrenciler sözlü çeviri eğitimleri esnasında bir çok teknolojik araçtan faydalanırlar. Bu teknolojik araçlar sırasıyla şu şekildedir:

- Kontrol paneli/ Konsolu

- Kulaklık

- Mikrofon

- Görüntü ekranı

- Ses kayıt cihazı 
Ülkemizde, yukarıdaki teknolojik araç donanımına sahip kabinlerin bulunduğu bazı üniversiteler ve kabin sayıları şu şekildedir: Hacettepe Üniversitesi (13), İstanbul Üniversitesi (2), Dokuz Eylül Üniversitesi (3), Ege Üniversitesi, Boğaziçi Üniversitesi (1), Bilkent Üniversitesi (1), İzmir Ekonomi Üniversitesi (8), Atılım Üniversitesi (5), Yıldız Teknik Üniversitesi (2).

Günümüzde teknoloji büyük bir ilerleme kaydetmiş ve bu ilerleme sayesinde çeviri ve çeviri eğitimi farklı bir boyuta geçmiştir. Özellikle sözlü çeviri eğitiminde teknoloji yardımıyla yaratılan farklı ortamlarda eğitim verme ve alma daha kolay bir hale gelmiştir. Dünyada ve ülkemizde sözlü çeviri eğitiminin farklı ortamlarda verilmesiyle ilgili çalışma örnekleri bulunmaktadır. Telefon yoluyla sözlü çeviri eğitimi (Ko, 2006, 2008; Wadensjö, 1999), sağlık alanında sözlü çeviri eğitiminin açık kaynak kodlu öğrenme ortamı olan Moodle üzerinden verilmesi (Tymczyńska, 2009), bilgisayar destekli sözlü çeviri araçlarının tasarlanması ve sözlü çeviriye etkisi (Sandrelli, 2005; Sandrelli ve De Manuel Jerez, 2007; Ko ve Chen, 2011), Ebru Diriker'in internet kaynaklarının sözlü çeviri eğitimindeki yeri ve önemini anlatan çalışması (Diriker 2010: 329-332), Jun Pan'ın eşzamanlı çeviri eğitiminde gerçek konferanslara benzer şekilde simüle edilmiş konferansların öğrencilerden alınan geri dönütler ve eğitmenlerin gözlemlerine göre faydalı ve uygulanabilir bir eğitim modeli olabileceğini ortaya koyduğu çalışması (Pan, 2016), Sabine Braun'un farklı sözlü çeviri ve konu alanlarında uzaktan eğitim konusunu hukuki bağlamda ele aldığı çalışması (Braun, 2017), Mehmet Şahin'in sanal dünyanın sözlü çeviri eğitiminde kullanılabilirliği konulu çalışmaları (Şahin, 2013; Şahin ve Eraslan, 2017) sözlü çeviri eğitiminin farklı ortamlarda verilmesiyle ilgili başlıca çalışmalardandır.

Bu çalışmalar arasından özellikle sanal dünyaların sözlü çeviri eğitiminde kullanılabilirliği konulu çalışmalar (Şahin, 2013; Şahin ve Eraslan, 2017) dikkat çekmektedir. Zira, sanal dünyalar teorik bilginin daha çok uygulamayla desteklenmesi ile profesyonel düzeye çıarılabilecek olan sözlü çeviri edimi için gerçeğe yakın ortamlar sunduğundan dolayı, ideal eklentiler olarak sözlü çeviri eğitimine ve edimine dâhil edilebilirler (Şahin, 2013). Böyle bir eğitim verilmesi ve alınması için çevirmenlerin ve çevirmen adaylarının bir uzman tarafından eğitim alması gerekir.

Sözlü çevirinin birçok farklı türü göz önünde bulundurulduğunda, sanal dünya içerisinde verilen eğitimin hem eğitmenler hem de çeviri eğitimi alan öğrenciler için eşsiz bir deneyim olacağı kanısındayız. Örneğin, konferans çevirmenliği için sanal dünyada bir konferans salonu tasarlanabilir ve öğrenciler ardıl ya da andaş çeviri türlerinde pratik yapabilirler. Ya da sanal bir mahkeme salonu tasarlanıp öğrencilerin mahkeme çevirmenliği deneyimi kazanmaları sağlanabilir. Tabi bu deneyimler sadece bu iki örnekle sınırlı kalmayarak afet çevirmenliği, kabiniçi andaş çeviri, kabindışı andaş çeviri, fısıldayarak çeviri, spor çevirmenliği gibi sözlü çeviri türlerinde de kazanılabilir. Sanal dünyanın sözlü çeviri eğitiminde en büyük avantajı, verilen sözlü çeviri eğitimine göre tasarlanması ve öğrencilerin bütün bunları internet bağlantısını kullanarak uzaktan katılması ve sınıfa ya da laboratuvara gitmeden yapmasidir.

Bu sanal dünya ile sözlü çeviri eğitimi verilen programlara başlıca Second Life (İkinci Hayat) ve IVY Project (Interpreting in Virtual Reality / Sanal Gerçeklikte Sözlü Çeviri) verilebilir. Second Life daha çok sosyal ve eğlence amaçlı kullanılan fakat sözlü çeviri eğitiminde de kullanılan, internet üzerinden çalışan ve içeriği tamamen kullanıcılar tarafından oluşturulan üç boyutlu bir sanal dünyadır. Dünyanın her yerinden katılabilen kullanıcılar bu sanal dünyada kendilerini bir avatarla temsil ederler. Second Life'ın kullanım esnekliği, yaratıcılı̆̆a özendirmesi, öğrenci motivasyonunu ve katılımı arttırması, gruplar ve kişiler arasında işbirliğini desteklemesi, mesafe engelini ortadan kaldırması, sosyal mevcudiyet 
duygusunu vermesi ve deneyime dayalı öğrenmeye olanak sağlaması, eğitim alanında kullanılmasında büyük bir etkendir.

IVY projesi Avrupa Komisyonu tarafından desteklenmesi ve özellikle sözlü çeviri alanına yönelik olması açısından bir önem taşımaktadır. Proje, Second Life'da olduğu gibi sanal bir ortamda tasarlanan çeviri ortamlarında sözlü çeviri yapmayı ve de eğitimini almayı mümkün kılar. Proje hakkında daha geniş bir bilgiye http://virtual-interpreting.net sitesinden ulaşılabilir.

Sözlü çeviri eğitiminde ardıl ve eşzamanlı çeviri derslerinin sanal olarak desteklendiği, Cenevre Üniversitesi tarafından kurulan Sanal Enstitü, 2004 yllında tercüman eğitmenleri için öncü bir çevrimiçi eğitim platformu olarak geliştirilmiş ve daha sonra öğrenci toplulukları için sanal eve dönüşmüştür. 2016 yılında yeni, geliştirilmiş, çevrimiçi bir eğitim konsepte geçilmiştir. Geçiş döneminde, Sanal Enstitü kayıtlı tüm yüksek lisans öğrencileri için erişilebilir olmaya devam etmiştir.

Sanal dünya teknolojisinin yanı sıra, sözlü eğitime yardımcı bir başka teknoloji olarak Moodle örnek verilebilir. Moodle, dünyanın birçok yerinde özellikle eğitim alanında kullanılan açık kaynak bir ders yönetim sistemidir. Moodle, en basit tanımıyla, çevrimiçi dersler ve bunlara bağlı web sayfaları oluşturmaya yarayan bir web yazılımıdır. Web yazılımından öte, eğitimin gelişmesine katkıda bulunmak amacıyla oluşturulmuş ortak katılımlı bir projedir (Aydın, 2003). İçerisinde sohbet, veritabanı, forum, sözlük, ders, quiz, anket ve wiki modüllerini kapsamasından dolayı hem yazılı hem de sözlü çeviri eğitiminde faydalı olmaktadır.

\section{Sonuç}

Medeniyetin var olmaya başladı̆̆ı andan itibaren, insanlar arası iletişimin ve etkileşimin gerçekleşmeye başladığı çă̆lardan bu yana var olan sözlü çeviri etkinliği, farklı alt türleriyle beraber akademik araştırmalara konu olmuştur. Teknolojinin hayatımızın her köşesini etkisi altına aldığı günümüzde, sözlü çeviri etkinliği de şüphesiz teknolojik araçlardan bağımsız düşünülemez.Yazılı çeviri teknolojilerinin gerek akademik araştırmalarda gerekse sektörel uygulamalarda oldukça yoğun olarak bahsedilmesine rağmen, sözlü çeviri teknolojileri bu bağlamda hak ettiği ilgiyi görmemektedir. Bahsedilen gerçeklikten hareket eden bu çalışma, sözlü çeviride kullanılan teknolojik araçların kullanış mantığını genel olarak tanıtmayı ve bu araçların sistematik bir sınıflandırma yapmasını hedeflemiştir. Bu bağlamda, sözlü çeviride kullanılan teknolojik araçlar; sözlü çeviride kullanım alanları, sözlü çevirinin farklı süreçlerinde kullanım durumları, sözlü çeviriye sağladıkları otomasyon derecesi ve sözlü çeviri eğitiminde kullanılan araçlar olmak üzere dört kategoride incelenmiştir. Araştırmacıların ilgili literatür okumaları ve bireysel teknolojik araç kullanım deneyimlerinden hareketle oluşturulan bu sınıflandırmada, sözlü çeviri teknolojilerinin hitap ettiği kullanıcı profilleri de mercek altına alınmıştır.

Alana dair bütüncül bir bakış açısı sunma ve bilgilendirici bir çalışma meydana getirmeyi hedefleyen araştırmacılar, bu çalışma ile sözlü çeviri teknolojileri alanında farkındalık uyandırmayı hedeflemektedirler. Her ne kadar ülkemizde bu alanda yeterince araştırma bulunmasa da uluslararası platformda bir yayın ağı mevcuttur. Çalışma kapsamında incelenen teknolojik araçların farklı kullanıcı profilleriyle denenmesi alana dair değerli katkılar sunacaktır. $\mathrm{Bu}$ doğrultuda, sözlü çeviri teknolojilerinin gerek nitel gerekse nicel araştırma yöntemleriyle, sözlü çeviri dünyasının farklı paydaşları tarafından kabul edilme düzeylerinin ölçülmesinin alana katkı sağlayacağı kanısındayız. Bilhassa Türkçenin çalışma dili olarak yer aldığı farklı sözlü çeviri teknolojilerinin; dilbilimsel, sözlükbilimsel ve pragmatic açıdan incelenmesinin bu teknolojik araçların geliştirilmesi anlamında 
yararlı olacağını düşünmekteyiz. Ayrıca, oldukça rekabete dayalı olan sözlü çeviri sektörüne kaliteli eleman istihdam etmeyi hedefleyen çeviribilim / mütercim-tercümanlık bölümlerinin, sözlü çeviride kullanılan teknolojik araçları sözlü çeviri eğitimine ne oranda entegre ettiklerinin araştırılması da alandaki ileri çalışmalara ilham verebilir.

\section{Kaynakça}

Alkan-Canım, S. (2013). Lisans düzeyinde çeviri eğitimiminde teknoloji eğitiminin yeri. $\dot{I} . \ddot{U}$ Çeviribilim Dergisi, s. 127-147.

Alkan-Canım, S. (2017). Bulut tabanlı bir çeviri yönetim sisteminin çevirmenler açısından avantaj ve dezavantajları üzerine bir değerlendirme. Electronic Turkish Studies. 12(23), 69-88.

Aktaş, T. (2013): Notationssprache als Gedächtnisunterstützendes mittel beim Konsekutivdolmetschen. Diyalog. Interkulturelle Zeitschrift für Germanistik, s. 81-90.

Andres, D. (2002): Konsekutivdolmetschen und Notation. Frankfurt am Main: Peter Lang Verlag.

Aslan, E. (2015). Çeviri teknolojilerinin çevirmenin sınırlarını belirlemedeki rolü. V. Uluslararası Karşılaştırmah Edebiyat Bilimi Kongresi. Mersin.

Aslan, E. (2016). Geçmişten günümüze çeviri teknolojileri. 2016 Hoca Ahmet Yesevi Yıl Anısına Uluslararası Türk Dünyası Eğitim Bilimleri Ve Sosyal Bilimler Kongresi.

Atik, G. (2011). Sözlü çeviri yöntem ve teknikleri. Ankara: Sinemis Yayınları.

Aydın, Ö. (2003): Yeni başlayanlar için Moodle: Genel bakış.Bilkent Üniversitesi.

Balkul, H. İ. (2017). Suriyeli sığınmacilara sunulan yazılı ve sözlü çeviri hizmetleri: Türkiye örneklemi ve Küresel Bakış. International Journal of Language Academy, 5(4) 102-112.

Balkul, H.I. (2018). A comparative analysis of translation/interpreting tools developed for Syrian refugee crisis. International Journal of Language Academy, 6(4), 32-44.

Bowker, L. ve M. Barlow. (Ağustos, 2004). Bilingual concordancers and translation memories: A comparative evaluation. Proceedings of the Second International Workshop on Language Resources for Translation Work, Research and Training. Association for Computational Linguistics, 70-79.

Braun, S. (2017). What a micro-analytical investigation of additions and expansions in remote interpreting can tell us about interpreters' participation in a shared virtual space. Journal of Pragmatics, 107, 165-177.

Bulut, A. ve Kurultay, T. (2001). Interpreters-in-aid at disasters: Community interpreting in the process of disaster management. The Translator. 7.2, s: 249- 263

Bührig, K. (1999). Konsekutives Übersetzen Englisch-Deutsch. Gerzymisch-Arbogast, Heidrun Gile, Daniel / House, Juliane / Rothkegel, Annely (Hg.): Wege der Übersetzungs - und Dolmetschforschung. Tübingen: Gunter Narr Verlag, s. 241-266.

Costa, H., Corpas Pastor, G., \& Durán Muñoz, I. (2014). Technology-assisted interpreting. MultiLingual, 143(25), 3 .

Çakır, A. (1994). Sözlü çeviri ve çeşitleri. Selçuk Üniversitesi Sosyal Bilimler Enstitüsü Dergisi. 3(1). 1318.

Daelemans, W. ve V. Hoste (Ed.). (2010). Evaluation of translation technology. Antwerp: Academic \& Scientific Publishers.

Demirdağ, H. E. (2013). Ardıl çeviri öğrenimi aşamasında dilsel hatalar: Birkaç ipucu. International Periodical For The Languages, Literature and History of Turkish or Turkic, 273-279.

Diriker, E. (2005). Konferans çevirmenliği : Güncel Uygulamalar ve Araştırmalar. Scala.

Diriker, E. (2010). Simultaneous conference interpreting and technology. Handbook ofTranslation Studies 1. Dü. Yves Gambier ve Luc van Doorslaer (ed.) 329-332. 
Doğan, A. (2002a). Ardıl çeviride dikkat odakları. Çeviribilim ve Uygulamaları, 12, 25-37.

Doğan, A. (2009). Sözlü çeviri, çahışmaları ve uygulamaları. Ankara.

Doherty, S. ve D. Kenny (2014). The design and evaluation of a statistical machine translation syllabus for Translation students. The Interpreter and Translator Trainer, 8.2, 295-315.

Durukan, E. (2017). Ardıl çeviri eğitiminde not almanın önemi ve not alma duyarlılığının pekiştirilmesi. Diyalog Interkulturelle Zeitschrift Für Germanistik, 102-112.

Eraslan, Ş. (2013). Ardıl çeviride kullanıcı beklentileri. İstanbul Üniversitesi Çeviribilim Dergisi, 57-85.

Esselink, B. (2000). A practical guide to localization. Amsterdam: John Benjamins Publishing.

Fantinuoli, C. (2016). InterpretBank. Redefining computer-assisted interpreting tools. Proceedings of the 38th Confrence Translating and the Computer, 42-52.

Fantinuoli, C. (2018). Computer-assisted Interpreting: Challenges and future perspectives. Konınklijke Brill NV.

Fantinuoli, C. ve Prandi, B. (2018). Teaching information and communication technologies. trans-kom, 162-182.

Garcia, I. (2009b). Research on translation tools. A. Pym ve A. Perekrestenko (Ed.). Translation Research Projects 2 içinde. Tarragona: Intercultural Studies Group, 27-33.

Gaspari, F. (Eylül 2001). Teaching machine translation to trainee translators: A survey of their knowledge and opinions. MT Summit VIII: Workshop on Teaching Machine Translation. Santiago de Compostela, Spain: 35-44.

Hutchins, W. J. ve H. L. Somers (1992). An introduction to machine translation. Londra: Academic Press.

Ivona Brizar (2014) Masterarbeit „Speech-to-Speech Translation Apps Ein kritischer Vergleich“ Uni Wien

Kahraman, R. (2010). Göç ve çeviri: İltica başvurularında sözlü çeviri uygulamaları vetoplum çevirmeninin rolï.Yayınlanmamış Doktora Tezi. İstanbul Üniversitesi, İstanbul

Kautz, U. (2002), Handbuch Didaktik des Übersetzens und Dolmetschens, München: Goethe Institut. 2. Baskı.

Ko, L. (2006). Teaching interpreting by distance mode.Interpreting 8.1 (67-96.

Ko, L. (2008). Teaching interpreting by distance mode: An empirical study.» Meta 53.4, 814-840.

Korkmaz, İ. ve Acar, E. N. (2017). SDL TradosStudio yazılımı üzerinden bilgisayar destekli çeviri teknolojileri. Dicle Üniversitesi Sosyal Bilimler Enstitüsü Dergisi. 9(19), 1-16.

Kurz, I. (2001). Conference interpreting: Quality in the ears of user. Meta, 46: 2, s: 384-410.

Kuşçu, E. (2015). Çeviride yapay zeka uygulamaları. Kazım Karabekir Eğitim Fakültesi Dergisi, 45-58.

Odacıŏ̆lu, M. C. (2017). Çeviribilimde Yerelleştirme Pradigmasına Doğru. İstanbul: Gece Kitaplı̆̆ı

O’Hagan, M. ve D. Ashworth (2002). Translation-mediated communication in a digital world. Clevedon: Multilingual Matters.

O'Hagan, M. (2012). The Impact of new technologies on Translation Studies: A technological turn? C. Millan-Varela, C. Millan ve F. Bartrina. (Ed.). Routledge Handbook of Translation Studies içinde. Londra / New York: Routledge, 503-518.

Özkaya, E. (2017). Sözlü çeviri araştırmalarında mecra dönüşümü. Trakya Üniversitesi Edebiyat Fakültesi Dergisi, 108-119.

Pan, J. (2016). Linking classroom exercises to real-life practice: a case of situatedsimultaneous interpreting learning.The Interpreter and Translator Trainer 10 (1), 107132. <http://dx.doi.org/10.1080/1750399X.2016.1154346>. 
Pöchhacker, F. (2000). Dolmetschen-Konzeptuelle Grundlagen und deskriptive Untersuchungen. Stauffenburg Verlag.

Pym, A. (2006). Asymmetries in the teaching of translation technology. Pym, A., A. Perekrestenko ve B. Starink (Ed.). Translation technology and its teaching içinde. Tarragona: Universitat Rovira i Virgili (Intercultural Studies Group) 113-124.

Samson, R. (2005). Computer assisted translation. M. Tennet (Ed.). Training for the new millenium: Pedagogies for Translation and Interpreting içinde. Amsterdam ve Philadelphia: John Benjamins, 101-122.

Şahin, M (2013). Çeviri ve teknoloji. İzmir: İzmir Ekonomi Üniversitesi Yayınları.

Şahin, M. (2015). Çevirmen adaylarının gözünden İngilizce-Türkçe bilgisayar çevirisi ve bilgisayar destekli çeviri: Google deneyi. Çeviribilim ve Uygulamaları Dergisi, 43-60.

Şahin, M. ve Eraslan, Ş. (2017). Sözlü çeviri eğitiminde yeni yaklaşımlar: Sanal dünyalar. M. Ş. Yetkiner içinde, Dilbilim Çeviribilim Yazıları. Anı Yayınları, 189-202.

Şan, F. (2013). The use of technology in academic translator training In the restructuring process of higher education. The Online Journal of Distance Education and e-Learning. 1.2, http://www.tojdel.net/volume/tojdel-volumeo1-io2.pdf\#page=34 (20.12.2013)

Taylor-Bouladon, V. (2001). Conference Interpreting: Principles and practice. Adelaide: Crawford House Publishing.

Tosun, M. ve Kabukcik, S. (2013). Genel çeviri kuramlarının sözlü çeviriye etkisi ve sözlü çeviriyi yazılı çeviriden ayıran özellikler. Yalova Sosyal Bilimler Dergisi, 174-181.

Yavanoğlu, U. ve Sağıroğlu, Ş. (2010). Web tabanlı otomatik dil tanıma ve çevirme sistemi. Gazi Üniversitesi Mühendislik- Mimarlkk Fakültesi Dergisi, 483-494.

Yetkiner, N. K., Oktar, L., Yavuz, Y. ve Özgen, M. (2015). Yazılı metinden sözlü çeviride akıcısızlık ve duraklar:. Hacettepe Üniversitesi Edebiyat Fakültesi Dergisi. 32(2), 103-118.

Yıldırım, C. (2017). Çeviri belleği sistemlerinde gerçekleştirilen çevirilerde çevirinin kalitesi ve çevirmenlerin görünürlüğ̈̈/ görünmezliği hususlarının değerlendirilmesi. Proceedings Book of 2nd International Scientific Researches Congress on Humanities and Social Sciences (IBAD2017). İstanbul. 